\title{
The Assessment of Emotion Regulation: Improving Construct Validity in Research on Psychopathology in Youth-An Introduction to the Special Section
}

\author{
Carl F. Weems • Armando A. Pina
}

Published online: 19 January 2010

(C) Springer Science+Business Media, LLC 2010

\begin{abstract}
This paper discusses issues in the assessment of emotion regulation in psychopathology research in youth and introduces a special section of the Journal of Psychopathology and Behavioral Assessment on the topic. The historical and practical importance of the concept of emotion regulation is noted and conceptual challenges in assessing emotion regulation are discussed. Empirical goals for improving construct validity in research on psychopathology and emotion regulation are discussed. We comment on how the papers in the special section advance understanding in these areas and suggest a multiple perspective and a multiple level of analysis approach for clarifying future research.
\end{abstract}

Keywords Emotion regulation · Assessment · Youth .

Psychopathology

Numerous definitions for the construct of emotion regulation exist (Calkins 2010, this issue). A broadly useful definition of emotion regulation is "the process of initiating, maintaining, modulating, or changing the occurrence, intensity, or duration of internal feeling states and emotion-related physiological processes, often in the service of accomplishing one's goals" (Eisenberg et al. 2000a, p. 137; see also Eisenberg 2002; Thompson et al. 2008). In children, emotion regulation has been linked to

C. F. Weems $(\bowtie)$

Department of Psychology, University of New Orleans,

New Orleans, LA 70148, USA

e-mail: cweems@uno.edu

A. A. Pina

Arizona State University,

Phoenix, AZ, USA emotional and behavioral problems as well as positive competencies (e.g., Eisenberg et al. 1996, 1998, 2007a, b; Kochanska and Knaack 2003; Riggs et al. 2003; Silk et al. 2003; Spinrad et al. 2006, 2007). Prolonged emotional dysregulation (e.g., hyperarousal associated with traumatic stress) is associated with hormonal dysregulation, academic difficulties, as well as structural brain changes and functional deficits in youth (e.g., Carrión et al. 2007, 2008; De Bellis 2001; Weems and Carrión 2007).

The regulation of emotion is clearly an important concept, although a highly complex one (Bridges et al. 2004; Calkins and Dedmon 2000; Eisenberg et al. 2000a, b; Gross 1999, 2002; Thompson 1991, Thompson 1994; Thompson et al. 2008). This complexity makes the valid and reliable assessment of emotion regulation no easy task and this special section was prompted by this important challenge. The special section was designed to further knowledge on the defining features of emotion regulation as well how it might be indexed particularly with regard to psychopathology in youth. In the following sections we provide a brief overview of history of the construct and then outline some of the key questions the special section was designed to address.

\section{A Brief History of the Emotion Regulation Construct}

Historically, as reviewed in Eisenberg (2002), the concept of emotion regulation can be traced back to early Greek philosophy such as in Plato's Republic (Book 9, trans. Reeve ) and to the writings of several more recent scholars who have influenced the development of psychology as a discipline (e.g., Bandura and Mischel 1965; Bowlby 1973; Locke 1964; Sears et al. 1957, 1965; Hoffman 1970, 1975). Indeed, the concept of emotional control or regulation is 
central to many ideas in European and Asian philosophical traditions. For example, the 17th century philosopher Spinoza was very interested in the emotions and wrote about the differences between negative emotional states (his term "passions") and positive ones ("emotions") and the importance of harnessing or regulating the passions (see Damasio 2003; Hergenhahn 2005). Similarly, there are a number of Eastern/Asian intellectual traditions (with origins 700 years BCE) which emphasize emotional control and practices for controlling emotional states (see e.g., Brefczynski-Lewis et al. 2007; Davidson and Lutz 2008).

Central and highly relevant to current conceptualizations of the construct of emotion regulation in developmental psychology, Rothbart and Derryberry (1981) defined temperament as reactivity, including emotional reactivity, and as an aspect of functioning that serves to regulate reactivity. The work of Block and Block (1980) on egoresilience also directly influenced current work on emotion regulation (Eisenberg 2002). For example, the Blocks were interested in the dysfunctional nature of over-control and the importance of flexible, optimal levels of control for successful adaptation. Research on temperament and coping as well as neurophysiological studies have also highlighted the need to examine different modes of the regulation of emotion (e.g., Derryberry and Rothbart 1997; Posner and Rothbart 1998).

A somewhat parallel literature has been emerging in the clinical and psychotherapeutic research literature. Aaron Beck (1976) and Albert Ellis (1962) wrote about the cognitive control of emotions and the importance of emotions and emotional expression in psychotherapy. For instance, Beck (1976) argued that dysfunctional cognitions such as catastrophizing (i.e., expecting the worst of an event or situation) will lead to negative emotional states such as fear and sadness. Similarly, Ellis (1962) argued that helping a client think differently about their lives and problems and to think more rationally could produce positive emotional change. Both of these authors emphasized the cognitive control of emotions and Ellis even suggested that people are capable of controlling ones emotional feelings by "...employing ones existing emotional states and prejudices..." (Ellis 1962, p. 40). While Beck and Ellis are both usually associated with the cognitive and behavioral revolution in psychotherapy it is clear they were also centrally interested in emotion regulation.

Presently, the proliferation of research on the topic is astounding. For instance Google scholar lists several thousand articles on "emotion regulation" and Psychinfo over 1,800 . There is also a burgeoning interest in utilizing the emotion regulation literature to inform treatment and in research on psychopathology. The titles of two recent commentaries published in the journal American Psychologist highlight the challenge posed by the complexity of the topic in this rapidly growing field. One commentary was titled "Is emotion regulation a useful construct that adds to the explanatory power of learning models of anxiety disorders or a new label for old constructs?" (Zinbarg and Mineka 2007) written in response to Olatunji et al.'s (2007) commentary, "Implications of emotion regulation for the shift from normative fear-relevant learning to anxiety-related psychopathology". Our hope is that this special section can help to address Zinbarg and Mineka's (2007) question broadly, not just for models of anxiety disorders but generally in terms of fostering the construct validity of emotion regulation in relation to psychopathology through improved understanding of the assessment of the construct.

In review and commentary papers written for this special section Cisler et al. (2010, this issue) and Lewis et al. (2010, this issue) continue this important discussion. Cisler et al. (2010, this issue) highlight the potential that the construct can make to understanding debilitating anxiety. While Lewis et al. (2010, this issue) underscore the need for improvement in understanding basic psychometric properties of measures of emotion regulation such as temporal stability (e.g., test re-test reliability) in relation to psychopathology.

In selecting empirical papers for this special section, we sought scholarship that helps to draw distinctions between the assessment of emotion regulation and related concepts. We also desired papers that address developmental and contextual issues in the assessment of emotion regulation and that highlight innovative methods of assessing the construct. In the remainder of this introduction to the special section, we lay out some important empirical goals for improving construct validity through assessment. We outline some key questions that research needs to clarify to address the question posed by Zinbarg and Mineka's (2007) comment regarding the utility of emotion regulation. We note how the papers in the special section move toward answering questions of construct validity and utility of emotion regulation assessment and suggest a multiple perspective and a multiple level of analysis approach for future research in this area.

\section{Conceptually and Empirically Clarifying the Nomological Net of Emotion Regulation}

Construct validity is critical to the assessment of any psychological concept. The consideration of basic issues in construct validity underscores challenges to the valid assessment of emotion regulation in relation to psychopathology (Salekin 2009). As proposed by Cronbach and Meehl (1955), construct validity requires that for a construct (and the way the construct is measured) to be valid, it must be incorporated into a theoretical structure, which they termed the "nomological net" (for relevant 
discussion see Stickle and Weems 2005; Weems and Stickle 2005). An adequate nomological net means a clear definition and explication of the prototypical elements that compose "emotion regulation" and that differentiate it from other constructs. For example, what facets compose emotion regulation versus facets of emotional problems/disorders versus emotional activation, versus independent factors that promote emotion regulation? (see also commentary by Calkins 2010, this issue; Lewis et al. 2010, this issue).

A conceptual example of this issue can be illustrated by our research on control in childhood anxiety disorders (Weems et al. 2003; Weems and Silverman 2006). Children's beliefs about their capacity to control anxiety related internal states, distinguishes children with anxiety disorders from their nonanxious peers (Weems et al. 2003). Moreover, these beliefs can be empirically distinguished from other negative cognitions such as negative cognitive errors, propensity for anxiety expression such as manifest anxiety, and other aspects of control such as locus of control (Weems et al. 2003, 2007). How does the concept of emotion regulation differ from the perceived ability to regulate anxiety? To some extent, the concept of emotion regulation concerns the real capacity to modulate emotional expression (Bridges et al. 2004) and thus implies a level of real control over emotional responses, for example, the real regulation of fear and anxiety symptoms in scary situations. Research suggests that youth with anxiety disorders actually have a relatively diminished capacity for controlling emotion (Suveg and Zeman 2004; but also see Lewis et al. 2010, this issue). It may, therefore, be methodologically important that operational definitions of emotion regulation are distinguishing between the child's perception of control and the actual capacity for emotion regulation. If not, the "new" research on the role of emotion regulation in childhood anxiety might indeed be replicating findings that are already known from the perceived control literature (Weems and Silverman 2006; For related discussion also see Zinbarg and Mineka 2007; Lewis et al. Similar issues exist for the concepts of temperament and emotion regulation and reactivity versus regulation as well, see Thompson et al. 2008, Calkins 2010, this issue).

On the other hand, the concept of emotion regulation might usefully subsume perceived control to the extent that perceived control is effective in emotion modulation (see Thompson et al. 2008 for related discussion). Some emotion level specificity may also facilitate the valid assessment of emotion regulation (e.g., anxiety versus sadness versus anger regulation Zeman et al. 2002; however, see also Calkins 2010, this issue). Emotion is not a unitary construct (see e.g., Davidson and van Reekum 2005) and so there is good reason to believe emotion regulation may not be fully tapped by a single construct either (e.g., its definition might span several related concepts/constructs).

In this special section, Carthy et al. (2010, this issue) expand on these important themes. Carthy et al. (2010, this issue) developed a new task to examine both emotional reactivity and regulation in anxious children. The new task involves presenting ambiguous situations with potentially threatening meanings to provoke real-time emotional activation in children using stimuli that resemble real-life situations. One aim of the task is to provide quantitative and qualitative assessments of individual differences in emotion reactivity and regulation. As discussed in the article, the task appears to be psychometrically robust. Interestingly, findings from the task revealed that children with anxiety seem to suffer from a combination of actual and perceived deficits in their regulation abilities. In addition, it appears that anxious children might feel less capable to regulate and seem to engage in the use of several strategies in search for something that would decrease their negative emotion.

Consistent with the work described in Carthy et al.'s article and also in this special section, Cisler et al. (2010, this issue) propose a model where emotion regulation may impact the development and maintenance of anxiety disorders. Briefly, Cisler and colleagues propose that individual differences in patterns of emotion regulation moderate the consequences of fear-conditioning processes. An aspect of Cisler et al.'s model builds on research showing that individuals with anxiety disorders appear to engage in relatively stable maladaptive patterns of emotion regulation. Although not directly articulated by Cisler et al., one such maladaptive pattern of emotion regulation could be that suggested by Carthy et al. where individuals who feel less capable to regulate seem to engage in the use of several regulation strategies in search for something that would decrease their negative emotion.

The papers in this special section also advance assessment knowledge on the issue of "what facets compose emotion regulation versus other things" in a number of ways. For example, Sulik et al. (2010, this issue) relied on state-of-the art modeling strategies to evaluate the construct validity of several assessment strategies linked to the broad emotion regulation net, specifically to "effortful control". Waters et al. (2010, this issue) describes data serving to disentangle the constructs of emotion regulation from attachment. The articles in the special section provide important advances in knowledge about the relations among the prototypical elements and processes of emotion regulation, and attempt a clearer discrimination between the construct of emotion regulation and other important and associated constructs (e.g., attachment, attention deficits, affect expression/activation, control). However, they also highlight the need for even more specific observations 
(empirical studies) to garner better understanding of the influence of the source of information (e.g., parent, child, and observation see commentary by Lewis et al. 2010, this issue). In fact, Calkins (2010, this issue) nicely points out in her commentary for this special issue that the distinction between reacting to an emotional stimulus and efforts to regulate that response may be artificial and difficult to disentangle unless research designs recognize that the two processes interact dynamically across time. Thus, static (or cross sectional) measurement of either may obscure true differences. Finally, even if measures of emotion regulation do not show incremental validity they may serve to improve the definitions/assessment of psychological problems such as the anxiety disorders (see e.g., Weems and Stickle 2005).

\section{Attending to Method Variance}

Another avenue for improving the assessment of the construct of emotion regulation in psychopathology research is to attend to the problem of method variance. Method variance refers to variability in scores on a trait measure (e.g., effortful control) resulting from something other than the trait (Campbell and Fiske 1959; Sechrest et al. 2000). Method variance can result from the characteristics of the informant, assessment situation, sample, or the assessment instruments/methods themselves. The construct validity of emotion regulation (in relation to psychopathology) may be further clarified by information on informant, instrument, and sample biases in its assessment. For example, a meta-analysis indicates that the average agreement among youth, parents, teachers, and clinicians is about $r=.25$ for measures of emotional and behavioral problems (Achenbach et al. 1987). It is unclear to what degree low informant reliability results from situational differences in behaviors (Achenbach et al. 1987), method variance (Stickle and Blechman 2002), inadequate assessment procedures (Sechrest et al. 1998), or poor construct validity (Sechrest et al. 1998, 2000). Method variance has been observed to account for twice as much variance as is accounted for by particular traits in studies of childhood psychopathology (Fergusson and Horwood 1989; Stickle and Blechman 2002). Thus, in addition to improving an understanding of the nomological net of emotion regulation, another way to improve construct validity is to use and understand the relations among multiple measures of the construct of emotion regulation as well as multiple measures of psychopathology (see Sechrest et al. 1998; Shadish et al. 2002; Stickle and Weems 2005). The papers in this special section are exemplary in using and combining multiple methods including computer based tasks, observational coding, electronic diaries, and self reports.
The importance of attending to method variance can also be highlighted by the idea of assessment contamination in examining emotion regulation and psychopathology (Mirabile 2009). For example, the Emotion Regulation Checklist (Shields and Cicchetti 1998) contains items that tap both emotional expression and emotion regulation and thus has some content highly similar to measures of psychopathology (potentially overlapping) such as externalizing problems (e.g., the CBCL; Achenbach 1991). In this special section, the articles of Sulik et al. (2010, this issue), Suveg et al. (2010, this issue), and Morris et al. (2010, this issue) serve to shed some important light on method variance. For example, Sulik et al. provide evidence for the cross-sex and cross-ethnic measurement equivalence of several effortful control tasks concluding that the specific aspects of effortful control do load on to a more general effortful control factor that is invariant across the above subsamples. The results of Suveg et al. (2010, this issue) suggest that an electronic diary method of assessing emotion states may offer unique information (although strategies to increase compliance in using this method are necessary).

\section{Level of Analysis}

The level of conceptual analysis (see Gewirtz 1969) required for studying particular phenomena within certain research programs may be best derived from different perspectives (Weems 1999) and so utilizing and contrasting different levels analysis may facilitate a clearer delineation of the interrelations between emotion regulation and psychopathology. Thus, in addition to clarifying the nomological net (conceptually and empirically) and attending to issues of method variance, Zeman et al. (2007) have outlined a model that may also help to improve assessment of emotion regulation in psychopathology research by focusing attention on at least three different levels of observation at which a construct can be assessed. On the theoretical level constructs are defined in the broadest manner. If measured on this level "emotion regulation" is likely to overlap with many similar constructs (e.g., attachment, negative affect). On the index level constructs are defined by the functional outcomes of specific behaviors. For example, and index-level measurement of emotion regulation might be measuring the consequences associated with fear or mood dysregulation and at this level there may also be significant overlap with measures of psychopathology (Mirabile 2009). It is important to note that while the assessment of emotion regulation at these levels will likely blur distinctions, such assessments may be practically important in the service of different goals (e.g., as a screening a for prevention intervention). 
At the skills level, constructs are measured by the specific skills associated with various aspects of, in this case, emotion regulation (e.g., actual regulatory strategies). In this special section, for example, Morris et al. (2010, this issue) focused on three specific emotion regulation skills/ strategies using a behavioral observation methodology: attention refocusing, comforting, and cognitive reframing. Results from Morris et al. showed that attention refocusing and cognitive reframing were associated with anger expression. However, comforting, attention refocusing, cognitive reframing did not predict significant unique variance in externalizing behavior problems beyond anger expression. Yet, some evidence for a more complex (or "dynamic" as discussed in Calkins 2010, this issue) set of relations did emerge. Specifically, attention refocusing was negatively associated with externalizing behavior (at $p<.10$ ) among children with high levels of anger reactivity but was not associated with externalizing behavior among children showing low levels of anger reactivity.

The findings of Morris et al. (2010, this issue) of potential interactive relations between expression and regulation and the results of Carthy et al. (2010, this issue) showing different profiles (implying a more person centered approach over group level interactions) of activation and regulation in anxious youth nicely highlight the complex interplay between emotion regulation and related constructs like emotion activation/expression (Calkins 2010, this issue). Examining the utility of different perspectives [incremental prediction/incremental validity unpacking constructs (Waters et al. 2010, this issue) versus interactive relations (Morris et al. 2010, this issue) versus different person centered profiles (Carthy et al. 2010, this issue)] and clarifying the level of analysis needed/being used for the research or intervention goals will ultimately serve to improve the clarity, utility, and validity of the construct of emotion regulation in research on psychopathology.

\section{Summary}

The conceptual and empirical delineation of critical prototypical elements that compose the construct of emotion regulation and that differentiate it from other constructs will advance confidence in the construct validity of emotion regulation in terms of its role in psychopathology. Research on the assessment of emotion regulation will also benefit from continued improvements in understanding the interrelations and unique properties of multiple measurement and assessment strategies (i.e., attending to method variance - self report versus, observation, versus physiological assessment) across multiple samples. Research detailing the characteristics of individual measures of emotion regulation and an accounting of how different modalities of assessment (e.g., self-report, parent report, interviews, behavioral observation, physiological measures) relate to each other can serve to clarify the relationships among the prototypical elements of emotion regulation and how these elements are associated both with related constructs and with psychopathology over time. This, we think, can be facilitated by a multiple perspective and multiple levels of analysis approach.

While the papers in this special section contribute to the knowledge base in a number of important ways, their greatest contribution (as all good science) may be in highlighting the next generation of research that is still needed. Thus, we end by thanking the authors and commentators for making this special section a reality. We hope you enjoy reading their work as much as we did and are confident that they will provide you important steps forward for future research.

\section{References}

Achenbach, T. M. (1991). Manual for the child behavior checklist/4-18 and 1991 profile. Burlington: University of Vermont Department of Psychiatry.

Achenbach, T. M., McConaughy, S. H., \& Howell, C. T. (1987). Child/ adolescent behavioral and emotional problems: implications of cross-informant correlations for situational specificity. Psychological Bulletin, 10, 213-232.

Bandura, A., \& Mischel, W. (1965). Modifications of self-imposed delay of reward through exposure to live and symbolic models. Journal of Personality and Social Psychology, 2, 698-705.

Beck, A. T. (1976). Cognitive therapy and the emotional disorders. New York: International Universities Press.

Block, J. H., \& Block, J. (1980). The role of ego-control and egoresiliency in the organization of behavior. In W. A. Collins (Ed.), Development of cognition, affect, and social relations: The Minnesota symposia on child psychology, Vol. 13 (pp. 39-101). Hillsdale: Erlbaum.

Bowlby, J. (1973). Attachment and loss: Vol. 2. Separation. New York: Basic Books.

Brefczynski-Lewis, J. A., Lutz, A., Schaefer, H. S., Levinson, D. B., \& Davidson, R. J. (2007). Neural correlates of attentional expertise in long-term meditation practitioners. Proceedings of the National Academy of Sciences, 104, 11483-11488.

Bridges, L. J., Denham, S. A., \& Ganiban, J. M. (2004). Definitional issues in emotion regulation research. Child Development, 75, 340-346.

Calkins, S. D. (2010, this issue). Commentary: conceptual and methodological challenges to the study of emotion regulation and psychopathology. Journal of Psychopathology and Behavioral Assessment, 32, doi:10.1007/s10862-009-9169-6.

Calkins, S. D., \& Dedmon, S. A. (2000). Physiological and behavioral regulation in 2-year-old children with aggressive/destructive behavior problems. Journal of Abnormal Child Psychology, 28, $103-118$

Campbell, D. T., \& Fiske, D. W. (1959). Convergent and discriminant validation by the multitrait-multimethod matrix. Psychological Bulletin, 56, 81-105. 
Carrión, V. G., Weems, C. F., \& Reiss, A. L. (2007). Stress predicts brain changes in children: a pilot longitudinal study on youth stress, PTSD, and the hippocampus. Pediatrics, 119, 509-516.

Carrión, V. G., Garrett, A., Menon, V., Weems, C. F., \& Reiss, A. L. (2008). Posttraumatic stress symptoms and brain function during a response-inhibition task: An fMRI study in youth. Depression and Anxiety, 25, 514-526.

Carthy, T., Horesh, N., Apter, A., \& Gross, J. J. (2010, this issue). Patterns of emotional reactivity and regulation in children with anxiety disorders. Journal of Psychopathology and Behavioral Assessment, 32, doi:10.1007/s10862-009-9167-8.

Cisler, J. M., Olatunji, B. O., Feldner, M. T., \& Forsyth, J. P. (2010, this issue). Emotion regulation and the anxiety disorders: an integrative review. Journal of Psychopathology and Behavioral Assessment, 32, doi:10.1007/s10862-009-9161-1.

Cronbach, L. J., \& Meehl, P. E. (1955). Construct validity in psychological tests. Psychological Bulletin, 52, 281-302.

Damasio, A. (2003). Looking for Spinoza: Joy, sorrow, and the feeling brain. Orlando: Harcourt.

Davidson, R. J., \& Lutz, A. (2008). Buddha's brain: neuroplasticity and meditation. IEEE Signal Processing, 25, 171-174.

Davidson, R. J., \& van Reekum, C. (2005). Emotion is not one thing. Psychological Inquiry, 16, 16-18.

De Bellis, M. D. (2001). Developmental traumatology: the psychobiological development of maltreated children and its implications for research, treatment, and policy. Development and Psychopathology, $13,539-564$.

Derryberry, D., \& Rothbart, M. K. (1997). Reactive and effortful processes in the organization of temperament. Development \& Psychopathology, 9, 633-652.

Eisenberg, N. (2002). Emotion-related regulation and its relation to quality of social functioning. In W. Hartup \& R. A. Weinberg (Eds.), Child psychology in retrospect and prospect: In celebration of the 75th anniversary of the Institute of Child Development (pp. 133-171). Mahwah: Erlbaum.

Eisenberg, N., Fabes, R. A., Karbon, M., Murphy, B. C., Wosinski, M., Polazzi, L., et al. (1996). The relations of children's dispositional prosocial behavior to emotionality, regulation, and social functioning. Child Development, 67, 974-992.

Eisenberg, N., Fabes, R. A., Shepard, S. A., Murphy, B. C., Jones, J., \& Guthrie, I. K. (1998). Contemporaneous and longitudinal prediction of children's sympathy from dispositional regulation and emotionality. Developmental Psychology, 34, 910-924.

Eisenberg, N., Fabes, R. A., Guthrie, I. K., \& Reiser, M. (2000a). Dispositional emotionality and regulation: their role in predicting quality of social functioning. Journal of Personality and Social Psychology, 78, 136-157.

Eisenberg, N., Guthrie, I. K., Fabes, R. A., Shepard, S., Losoya, S., Murphy, B. C., et al. (2000b). Prediction of elementary school children's externalizing problem behaviors from attention and behavioral regulation and negative emotionality. Child Development, $71,1367-1382$.

Eisenberg, N., Ma, Y., Chang, L., Zhou, Q., West, S. G., \& Aiken, L. (2007a). Relations of effort control, reactive undercontrol, and anger to Chinese children's adjustment. Development and Psychopathology, 19, 385-409.

Eisenberg, N., Michalik, N., Spinrad, T. L., Hofer, C., Kupfer, A., \& Valiente, C. (2007b). The relations of effortful control and impulsivity to children's sympathy: a longitudinal study. Cognitive Development, 22, 544-567.

Ellis, A. (1962). Reason and emotion in psychotherapy. New Jersey: Citadel.

Fergusson, D. M., \& Horwood, L. J. (1989). Estimation of method and trait variance in ratings of conduct disorder. Journal of Child Psychology and Psychiatry, 30, 365-378.
Gewirtz, J. L. (1969). Levels of conceptual analysis in environmentinfant interaction research. Merrill-Palmer Quarterly of Behavior and Development, 15, 7-47.

Gross, J. J. (1999). Emotion regulation: past, present, future. Cognition and Emotion, 13, 551-573.

Gross, J. J. (2002). Emotion regulation: affective, cognitive, and social consequences. Psychophysiology, 39, 281-291.

Hergenhahn, B. R. (2005). An introduction to the history of psychology. Belmont: Wadsworth.

Hoffman, M. L. (1970). Moral development. In P. H. Mussen (Ed.), Carmichael's manual of child development, Vol. 2 (pp. 261-359). New York: Wiley.

Hoffman, M. L. (1975). Moral internalization, parental power and the nature of parent-child interaction. Developmental Psychology, $11,228-239$.

Koschanska, G., \& Knaack, A. (2003). Effortful control as a personality characteristic of young children: antecedents, correlates, and consequences. Journal of Personality, 71, 1087-1112.

Lewis, A. R., Zinbarg, R. E., \& Durbin, C. E. (2010, this issue). Advances, problems, and challenges in the study of emotion regulation: a commentary. Journal of Psychopathology and Behavioral Assessment. doi:10.1007/s10862-009-9170-0.

Locke, J. (1964). Some thoughts concerning education (abridged and edited by F. W. Garforth). Woodbury, NY: Barron's Educational Series.

Mirabile, S. P. (2009). Emotion socialization, emotional competence, and social competence and maladjustment in early childhood. Unpublished Doctoral Dissertation, University of New Orleans, New Orleans, LA.

Morris, A. S., Silk, J. S., Steinberg, L., Terranova, A., \& Kithakye, M. (2010, this issue). Current and longitudinal links between children's externalizing behavior in school and observed anger regulation in the mother-child dyad. Journal of Psychopathology and Behavioral Assessment, 32, doi:10.1007/s10862-009-9166-9.

Olatunji, B. O., Forsyth, J. P., \& Feldner, M. T. (2007). Implications of emotion regulation for the shift from normative fear-relevant learning to anxiety-related psychopathology. American Psychologist, 62, 257-259.

Posner, M. I., \& Rothbart, M. K. (1998). Attention, self-regulation, and consciousness. Transactions of the Philosophical Society of London, B, 353, 1915-1927.

Riggs, N. R., Blair, C. B., \& Greenberg, M. T. (2003). Concurrent and 2-year longitudinal relations between executive function and the behavior of 1st and 2nd grade children. Child Neuropsychology, 9, 267-276.

Rothbart, M. K., \& Derryberry, D. (1981). Development of individual differences in temperament. In M. E. Lamb \& A. L. Brown (Eds.), Advances in developmental psychology, Vol. 1 (pp. 3786). Hillsdale: Erlbaum.

Salekin, R. T. (2009). Psychopathology and assessment: contributing knowledge to science and practice. Journal of Psychopathology and Behavioral Assessment, 31, 1-6.

Sears, R. R., Maccoby, E. E., \& Levin, H. (1957). Patterns of child rearing. Evanston: Row, Peterson.

Sears, R. R., Rau, L., \& Alpert, R. (1965). Identification and child rearing. Stanford: Stanford University Press.

Sechrest, L., Stickle, T.R., \& Stewart, M. (1998). The role of assessment in clinical psychology. In A. Bellack \& M. Hersen (Series eds.) \& C.R. Reynolds (Vol Ed.), Comprehensive clinical psychology, Vol. 4: Assessment (Chap 1). Oxford: Pergamon.

Sechrest, L., Davis, M., Stickle, T. R., \& McKnight, P. (2000). Understanding method variance. In L. Bickman (Ed.), Research design: David Campbell's legacy, Vol. 2. Thousand Oaks: Sage.

Shadish, W. R., Cook, T. D., \& Campbell, D. T. (2002). Experimental and quasi-experimental designs for generalized causal inference. Boston: Houghton Mifflin. 
Shields, A., \& Cicchetti, D. (1998). Reactive aggression among maltreated children: the contributions of attention and emotion dysregulation. Journal of Clinical Child Psychology, 27, 1998.

Silk, J. S., Steinberg, L., \& Morris, A. S. (2003). Adolescents' emotion regulation in daily fife: links to depressive symptoms and problem behavior. Child Development, 74, 1869-1880.

Spinrad, T. L., Eisenberg, N., Cumberland, A., Fabes, R. A., Valiente, C., \& Shepard, S. A. (2006). Relation of emotion-related regulation to children's social competence: a longitudinal study. Emotion, 6, 498-510.

Spinrad, T. L., Eisenberg, N., Gaertner, B., Popp, T., Smith, C. L., \& Kupfer, A. (2007). Relations of maternal socialization and toddlers' effortful control to children's adjustment and social competence. Developmental Psychology, 43, 1170-1186.

Stickle, T. R., \& Blechman, E. (2002). Aggression and fire: antisocial behavior in firesetting and non-firesetting juvenile offenders. Journal of Psychopathology and Behavioral Assessment, 24, $177-193$.

Stickle, T. R., \& Weems, C. F. (2005). Improving prediction from clinical assessment: The roles of measurement, psychometric theory, and decision theory. In R. R. Bootzin \& P. E. McKnight (Eds.), Strengthening research methodology: Psychological measurement and evaluation. Washington: American Psychological Association.

Sulik, M. J., Huerta, S., Zerr, A. A., Eisenberg, N., Spinard, T. L., Valiente, C., et al. (2010, this issue). The factor structure of effortful control and measurement invariance across ethnicity and sex in a high-risk sample. Journal of Psychopathology and Behavioral Assessment, 32, doi:10.1007/s10862-009-9164-y.

Suveg, C., \& Zeman, J. (2004). Emotion regulation in children with anxiety disorders. Journal of Clinical Child and Adolescent Psychology, 33, 750-759.

Suveg, C., Payne, M., Thomassin, K., \& Jacob, M. L. (2010, this issue). Electronic diaries: a feasible method of assessing emotional experience in youth? Journal of Psychopathology and Behavioral Assessment, 32, doi:10.1007/s10862-009-9162-0.

Thompson, R. A. (1991). Emotional regulation and emotional development. Educational Psychology Review, 3, 269-307.

Thompson, R. A. (1994). Emotion regulation: a theme in search of definition. (Ed.), Monographs of the Society for Research in Child Development, 59, 25-52.
Thompson, R. A., Lewis, M. D., \& Caulkins, S. D. (2008). Reassessing emotion regulation. Child Development Perspectives, 2, 124-131.

Waters, S. F., Virmani, E. A., Thompson, R. A., Meyer, S., Raikes, H. A., \& Jochem, R. (2010, this issue). Emotion regulation and attachment: unpacking the two constructs and their association. Journal of Psychopathology and Behavioral Assessment, 32, doi.10.1007/s10862-009-9163-z.

Weems, C. F. (1999). Psychological inquiry and the role of world views. Behavior and Philosophy, 27, 147-163.

Weems, C. F., \& Carrión, V. G. (2007). The association between PTSD symptoms and salivary cortisol in youth: the role of the time since the trauma. Journal of Traumatic Stress, 20, 903-907.

Weems, C. F., \& Silverman, W. K. (2006). An integrative model of control: implications for understanding emotion regulation and dysregulation in childhood anxiety. Journal of Affective Disorders, 91, 113-124.

Weems, C. F., \& Stickle, T. R. (2005). Anxiety disorders in childhood: casting a nomological net. Clinical Child and Family Psychology Review, 8, 107-134.

Weems, C. F., Silverman, W. K., Rapee, R., \& Pina, A. A. (2003). The role of control in childhood anxiety disorders. Cognitive Therapy and Research, 27, 557-568.

Weems, C. F., Costa, N. M., Watts, S. E., Taylor, L. K., \& Cannon, M. F. (2007). Cognitive errors, anxiety sensitivity, and anxiety control beliefs: their unique and specific associations with childhood anxiety symptoms. Behavior Modification, 31, 174201.

Zeman, J., Shipman, K., \& Suveg, C. (2002). Anger and sadness regulation: predictions to internalizing and externalizing symptoms in children. Journal of Clinical Child and Adolescent Psychology, 31, 393-398

Zeman, J., Klimes-Dougan, B., Cassano, M., \& Adrian, M. (2007). Measurement issues in emotion research with children and adolescents. Clinical Psychology: Science and Practice, 14, 377-401.

Zinbarg, R. E., \& Mineka, S. (2007). Is emotion regulation a useful construct that adds to the explanatory power of learning models of anxiety disorders or a new label for old constructs? American Psychologist, 62, 259-261. 